\title{
STUDI KOMPARATIF PROKRASTINASI AKADEMIK PADA SISWA YANG MENGIKUTI EKSTRAKURIKULER DENGAN YANG TIDAK MENGIKUTI EKSTRAKURIKULER DI SMA NEGERI 1 KENDARI
}

\author{
COMPARATIVE STUDY OF ACADEMIC PROCRASTINATION AT \\ STUDENTS WHO FOLLOW EXTRACURRICULARS ACTIVITIES WITH \\ STUDENT WHO NOT FOLLOWING EXTRACURRICULARS ACTIVITIES \\ IN SMAN 1 KENDARI
}

\author{
Wiwied Tri Dayanti ${ }^{1}$, Aspin ${ }^{2}$, Sitti Mikarna Kaimuddin ${ }^{3}$ \\ Program Studi Psikologi
}

Fakultas Keguruan dan Ilmu Pendidikan, Universitas Halu Oleo wiwid.tridavanti88@gmail.com ${ }^{1}$, aspin.psi@gmail.com ${ }^{2}$, mikarna.psikologi@gmail.com ${ }^{3}$

\begin{abstract}
ABSTRAK : Penelitian ini bertujuan untuk mengetahui: (1) Bagaimana tingkatan prokrastinasi akademik siswa yang mengikuti ekstrakurikuler, (2) Bagaimana tingkatan prokrastinasi akademik siswa yang tidak mengikuti ekstrakurikuler, (3) Bagaimana perbandingan prokrastinasi pada siswa yang mengikuti ekstrakurikuler dengan yang tidak mengikuti ekstrakurikuler. Jenis penelitian ini kuantitatif dengan desain penelitian studi kausal komparatif. Populasi dalam penelitian ini adalah kelas XI dengan sampel sebanyak 29 siswa yang mengikuti ekstrakurikuler dan 34 siswa yang tidak mengikuti ekstrakurikuler. Teknik pengumpulan data pada penelitian ini yaitu menggunakan skala prokrastinasi akademik. Uji hipotesis dilakukan dengan menggunakan uji t pada program SPSS 21.0 dengan taraf signifikan $p=0,05$. Hasil penelitian menunjukkan: (1) Prokrastinasi akademik siswa yang mengikuti ekstrakurikuler terkategori sedang,(2) Prokrastinasi akademik siswa yang tidak mengikuti ekstrakurikuler juga terkategori sedang,(3) Hasil uji t memperoleh nilai signifikansi 0,037 >0,05, maka artinya terdapat perbandingan prokrastinasi akademik siswa yang mengikuti ekstrakurikuler dan siswa yang tidak tidak mengikuti ekstrakurikuler.
\end{abstract}

Kata kunci: Ekstrakurikuler, Prokrastinasi Akademik.

ABSTRACT : This research aimed to determine: (1) The levels of academic procrastination of students who take extracurricular activities, (2) How are the differences levels of academic procrastination in students who do not take extracurricular activities, (3) How does procrastination compare to students who take extracurricular activities with those who do not take extracurricular activities. This type of research is quantitative with a comparative causal study research design. The population in this research was class XI with a sample of 29 students who took extracurricular activities and 34 students who did not take extracurricular activities. Data collection techniques in this study are using academic procrastination scale. Hypothesis testing is done using the t test in the SPSS 21.0 program with a significant level of $p=0.05$. The results showed: (1) Academic procrastination of students who take extracurricular activities showed the medium categorized, (2) Academic procrastination of students who do not take extracurricular activities also showed medium category, (3) T-test results obtained a significance value of 0.037>0.05, so that means there is a comparison of procrastination academic of students who take extracurricular activities and students who do not take extracurricular activities.

Keywords : Extracurricular, Academic Procrastination. 


\section{Pendahuluan}

Pendidikan berperan penting dalam rangka menciptakan manusia yang seutuhnya dan dapat bermanfaat bagi dirinya sendiri, keluarga, masyarakat dan bangsa. Pendidikan pada dasarnya merupakan suatu upaya untuk memberikan pengetahuan, wawasan, keahlian dan keterampilan kepada individu untuk mengembangkan potensi-potensi yang ada dalam diri individu, sehingga dapat menjalani hidup yang lebih bermakna. Hal ini sesuai dengan tujuan pendidikan nasional dalam Undang-Undang Nomor 20 tahun 2003 pada Bab II pasal 3 yaitu Pendidikan Nasional bertujuan untuk berkembangnya potensi peserta didik agar menjadi manusia yang beriman dan bertakwa kepada Tuhan Yang Maha Esa, berakhlak mulia, sehat, berilmu, cakap, kreatif, mandiri dan menjadi warga negara yang demokratis serta bertanggung jawab (Ristekdikti, 2016). Oleh karena itu, pelaksanaan pendidikan perlu didukung oleh partisipasi aktif pemerintah, berbagai kelompok masyarakat dan orang tua (Marliani, 2015).

Sekolah negeri pada umumnya memiliki tiga jenis kegiatan kurikulum yaitu: (1) Intrakurikuler (2) Kokurikuler (3) Ekstrakurikuler. Kegiatan intrakurikuler adalah kegiatan yang dilakukan oleh sekolah yang sudah teratur, jelas, dan terjadwal dengan sistematik yang merupakan program utama dalam proses mendidik siswa. Kegiatan kokurikuler adalah kegiatan yang menunjang dan membantu kegiatan intrakurikuler. Kegiatan ekstrakurikuler adalah kegiatan yang dilaksanakan di luar jam pelajaran biasa (Kemdikbud, 2017).

Ada 10 Sekolah Menengah Atas Negeri (SMAN) di Kota Kendari dan satu diantaranya SMAN 1 Kendari memiliki jenis kegiatan ekstrakurikuler terbanyak dibanding SMA Negeri lainnya yaitu sebanyak 20 jenis kegiatan ekstrakurikuler pilihan yang bersifat aktif. Diantaranya adalah (1) Persatuan Remaja Islam
SMANSA (2) Perserikatan Siswa Kristen (3) Gabungan Siswa Katolik (4) Persatuan Siswa Hindu Dharma(5) Komite Keamanan Sekolah(6) Pers \& Mading Smansa (7) Pelajar Cerdas Komunikasi (8) FILATELI (9) Karya Ilmiah Remaja (10) Komite Olahraga Siswa SMANSA (11) Koperasi Siswa SMANSA (12) Siswa Sadar Lingkungan (13) Palang Merah Remaja (14) Praja Muda Karana (15) Circle English Conversation Club (16) Gita Mandala Nuansa Marching Band (17) E-Robotic (18) Sanggar Seni (19) Siswa Pencinta Alam (20) Pasukan Pengibar Bendera. Dan kebanyakan siswa yang aktif dalam kegiatan ekstrakurikuler adalah siswa kelas XI.

Peneliti melakukan wawancara dengan salah satu guru wali kelas XI yang mempunyai siswa yang mengikuti ekstrakurikuler sebanyak 19 siswa dan siswa yang tidak mengikuti ekstrakurikuler sebanyak 17 siswa mengatakan terdapat perbedaan pada siswa yang mengikuti ekstrakurikuler dengan yang tidak mengikuti ekstrakurikuler terutama pada saat di dalam kelas beberapa siswa yang mengikuti ekstrakurikuler seperti olahraga basket sering merasa kelelahan di dalam kelas karena sering adanya pertandingan yang membutuhkan banyak latihan dari sore hari hingga malam hari sehingga siswa sering merasa kelelahan pada saat di dalam kelas.

Peneliti juga melakukan wawancara dengan beberapa siswa yang mengikuti ekstrakurikuler dikelas XI SMA Negeri 1 Kendari. Peneliti menemukan fenomena bahwa: (1) Siswa memilih kegiatan ekstrakurikuler berdasaran minat, bakat dan hobi (2) Siswa lebih senang mengikuti kegiatan ekstrakurikuler dibanding kegiatan intrakurikuler (3) Banyaknya kegiatan yang diikuti siswa baik didalam sekolah maupun diluar sekolah membuat siswa kesulitan membagi waktu antara kegiatan intrakurikuler, kokurikuler, dan ekstrakurikuler dan tergesa-gesa dalam mengumpulkan pekerjaan rumah (PR) (4) 
Ketika siswa harus mengerjakan PR, siswa tidak langsung mengerjakan PRnya melainkan menundanya dan lebih senang berkumpul dengan teman-teman di area sekolah maupun di luar sekolah (5) Beberapa kegiatan ekstrakurikuler memakan banyak waktu seperti kegiatan ekstrakurikuler Komite Olahraga Siswa SMANSA contohnya pada olahraga basket, siswa terkadang latihan hingga malam hari (6) Kurangnya konsentrasi dalam proses pembelajaran dikarenakan badan yang kurang bugar.

Hal ini menunjukkan bahwa tidak semua siswa memiliki kemampuan untuk mengatur waktu dengan baik, banyaknya kegiatan yang diikuti siswa menyebabkan siswa kurang memperhatikan pekerjaan rumah (PR) yang diberikan oleh guru sehingga siswa cenderung menundamenunda untuk mengerjakannya dan terkadang terburu-buru dalam menyelesaikannya. Sebagaimana yang dikatakan Jannah \& Muis (2014) tidak semua siswa memiliki kemampuan untuk mengatur waktu dengan baik, terutama ini biasanya terjadi pada siswa yang mengikuti kegiatan ekstrakurikuler atau organisasi di sekolah, sering kali siswa malas menghadapi tugas-tugas sekolah dan siswa cenderung melakukan penundaan tugas akan cenderung mengerjakannya terburuburu.

Tuckman (1990) menjelaskan bahwa prokratinasi adalah ketidakmampuan mengatur diri sendiri sehingga terjadi penundaan pekerjaan yang seharusnya berada dibawah kendali atau penguasaan diri tersebut. Seseorang yang melakukan penundaan akan merasa bahwa bila mengalami kegagalan atau hasilnya tidak memuaskan itu bukan karena rendahnya kemampuan, akan tetapi ketidak sungguhan dalam mengerjakan tugas yang dihadapi yaitu dengan menunda-nunda, karena tugasnya merupakan bagian dari aktivitas akademik, maka dapat disebut prokrastinasi akademik.
Menurut Rakhmanti (2014) dampak positif siswa yang mengikuti ekstrakurikuler adalah siswa mendapatkan wawasan akademik maupun wawasan nonakademik, mengenal banyak siswa baik dilingkungan sekolah maupun diluar sekolah ketika mengadakan pertandingan persahabatan, mengembangkan hobi atau sarana penyaluran bakat yang mereka miliki, memiliki berkepribadian yang baik dan mandiri, memiliki tanggung jawab dan membentuk karateristik siswa.

Berdasarkan hasil kuesioner yang peneliti berikan pada sebagian siswa yang tidak mengikuti ekstrakurikuler dikelas XI SMA Negeri 1 Kendari. Peneliti menemukan fenomena bahwa: Sebagian siswa memiliki banyak waktu luang namun cenderung mengerjakan PR ketika deadline sudah dekat

Bergantung pada orang, rasa bergantung terhadap teman dan berpikir bahwa PR bisa dikerjakan dengan melihat PR milik teman, membuat alasan untuk tidak atau menunda-nunda mengerjakan PR menjadi lebih besar (3) Banyaknya waktu luang yang dimiliki siswa membuat siswa menunda-nunda pengerjaan PR (4) Ketertarikan, sebagian siswa memiliki ketertarikan pada mata pelajaran tertentu sehingga PR pada pelajaran yang tidak terlalu diminati kadang siswa sering menunda untuk mengerjakannya.

Penelitian ini bertujuan: (1) Untuk mengetahui bagaimana tingkatan sangat tinggi, tinggi, sedang, rendah prokratinasi akademik siswa yang mengikuti ekstrakurikuler (2) Untuk mengetahui bagaimana tingkatan sangat tinggi, tinggi, sedang, rendah prokratinasi akademik siswa yang tidak mengikuti ekstrakurikuler (3) Untuk mengetahui bagaimana perbandingan prokratinasi pada siswa yang mengikuti ekstrakurikuler dengan yang tidak mengikuti ekstrakurikuler.

Penelitian ini memiliki beberapa manfaat yakni secara teoritis dan praktis. Pertama, manfaat teoritis dari penelitian ini adalah penelitian ini dapat menambah 
khasanah keilmuan dalam bidang psikologi, sosial maupun perkembangan serta dapat bermanfaat untuk membangun kajian ilmu psikologi karena menyangkut permasalahan dalam masa remaja. Kedua, manfaat praktis yaitu: (a) Penelitian ini dapat dipakai sebagai informasi tambahan bagi penelitian sejenis dalam bidang psikologi (b) Penelitian ini diharapkan dapat memberikan informasi sebagai bahan kebijakan dalam hal pembinaan di sekolah serta dapat digunakan sebagai antisipasi untuk meningkatkan kasus prokratinasi akademik pada siswa yang mengikuti ekstrakurikuler dengan siswa yang tidak mengikuti ekstrakurikuler di SMA Negeri 1 Kendari (c) Penelitian ini diharapkan dapat memberikan informasi mengenai gambaran yang jelas tentang perbandingan prokratinasi akademik pada siswa yang mengikuti ekstrakurikuler dengan siswa yang tidak mengikuti ekstrakurikuler di SMA Negeri 1 Kendari sehingga dapat bermanfaat bagi siswa-siswi yang hendak melakukan penelitian.

\section{Metode Penelitian}

Penelitian ini dilakukan pada tanggal 8 s/d 11 November 2019 di SMA Negeri 1 Kendari.

Jenis penelitian ini kuantitatif dengan desain penelitian studi kausal komparatif biasanya melibatkan dua atau lebih kelompok dan satu variabel bebas (Emzir, 2014). Berikut desain penelitian:

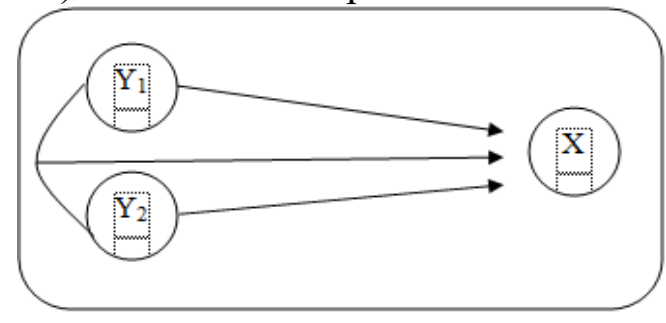

Gambar 1. Desain penelitian

Variabel yang digunakan dalam penelitian ini adalah variabel bebas (X) yaitu prokrastinasi akademik dan membandingkan dua kelompok yaitu kelompok siswa yang mengikuti ekstrakurikuler disimbolkan dengan $\mathrm{Y}_{1}$ dan kelompok siswa yang tidak mengikuti ekstrakurikuler disimbolkan dengan $\mathrm{Y}_{2}$.

Definisi operasional variabel dalam penelitian ini adalah prokrastinasi akademik yang dimaksud dalam penelitian ini adalah perilaku yang dilakukan siswa dengan menunda pekerjaan rumah yang diberikan oleh guru secara sengaja dan berulang-ulang, sering mengalami keterlambatan dalam menyelesaikan pekerjaan rumah sesuai batas waktu yang telah ditentukan.

Populasi dalam penelitian ini adalah seluruh siswa kelas XI SMA Negeri 1 Kendari yang berjumlah 427 siswa yang mempunyai rincian siswa yang mengikuti ekstrakurikuler sebanyak 267 siswa dan siswa yang tidak mengikuti ekstrakurikuler adalah sebanyak 160 siswa. Dalam penelitian ini, pengambilan sampel dilakukan dengan pertimbangan mengambil satu kelas dengan frekuensi siswa yang mengikuti ekstrakurikuler terbanyak dan satu kelas dengan frekuensi siswa yang tidak mengikuti ekstrakurikuler terbanyak. Sehingga terpilih kelas XI MIPA 1 sebanyak 29 siswa sebagai sampel siswa yang mengikuti ektrakurikuler $\left(\mathrm{Y}_{1}\right)$ dan terpilih kelas XI MIPA 5 sebanyak 34 siswa sebagai sampel siswa yang tidak mengikuti ektrakurikuler $\left(\mathrm{Y}_{2}\right)$ sehingga jumlah sampel pada penelitian ini 63 orang.

Teknik pengumpulan data yang digunakan peneliti adalah alat ukur, valditas dan reliabilitas. Pemberian skor pada penelitian ini menggunakan bentuk skala Likert berupa 4 pilihan jawaban yaitu Sangat Sesuai (SS), Sesuai (S), Tidak Sesuai (TS), Sangat Tidak Sesuai (STS).

Teknik analisis data yang digunakan dalam penelitian ini yaitu uji analisis deskriptif untuk mencari mean, standar deviasi dan uji analisis inferensial, untuk mengetahui apakah data terdistribusi secara normal dan untuk mengetahui apakah kedua kelompok memiliki 
homogen yang sama atau tidak, dengan tahapan sebagai berikut:

a. Uji Normalitas, menggunakan teknik Kolmogrov-Smirnov.

b. Uji Homogenitas, menggunakan uji Levene.

c. Uji Hipotesis, menggunakan uji t.

\section{Hasil Penelitian dan Pembahasan \\ Hasil Penelitian \\ Analisis Deskriptif}

\section{a) Deskriptif Subjek Penelitian}

Berdasarkan kategorisasi prokrastinasi akademik pada perempuan dan laki-laki siswa yang mengikuti ekstrakurikuler dari 29 total subjek penelitian $37,93 \%$ atau 11 siswa diantaranya ialah perempuan yang dimana 2 siswa berada pada kategori sangat tinggi, 1 siswa berada dalam kategori tinggi, 5 siswa berada dalam kategori sedang, dan 3 siswa berada dalam kategori rendah. Sedangkan $62,07 \%$ atau 18 siswa ialah laki-laki yang dimana 2 siswa berada pada kategori sangat tinggi, 2 siswa berada dalam kategori tinggi, 10 siswa berada dalam kategori sedang, dan yang terakhir 4 siswa berada dalam kategori rendah. Dari hasil jumlah presentasi kategorisasi prokrastinasi akademik pada perempuan dan laki-laki pada siswa yang mengikuti ekstrakurikuler pada kelas XI SMA Negeri 1 Kendari bahwa prokrastinasi akademik pada laki-laki lebih besar dibandingkan perempuan.

Siswa yang tidak mengikuti ekstrakurikuler dari 34 total subjek penelitian $55,88 \%$ atau 19 siswa diantaranya ialah perempuan yang dimana 1 siswa berada pada kategori sangat tinggi, 3 siswa berada dalam kategori tinggi, 9 siswa berada dalam kategori sedang, dan 6 siswa berada dalam kategori rendah. Sedangkan $44,12 \%$ atau 15 siswa ialah laki-laki yang dimana 2 siswa berada pada kategori sangat tinggi, 5 siswa berada dalam kategori tinggi, 4 siswa berada dalam kategori sedang, dan yang terakhir 4 siswa berada dalam kategori rendah. Dari hasil jumlah presentasi pengkategorisasian pada perempuan dan laki-laki pada siswa yang tidak mengikuti ekstrakurikuler pada kelas XI SMA Negeri 1 Kendari bahwa prokrastinasi akademik pada perempuan lebih besar dibandingkan pada laki-laki.

\section{b) Deskriptif Data Penelitian}

Tabel 1. Deskriptif data siswa yang mengikuti ekstrakurikuler dan yang tidak mengikuti ekstrakurikuler

\begin{tabular}{llcc}
\hline & N & Mean & SD \\
\hline Ektrakurikuler & 29 & 63,8679 & 5,18537 \\
\hline Non- & 34 & 61,5338 & 3,97923 \\
Ektrakurikuler & & & \\
\hline
\end{tabular}

Nilai mean pada siswa yang mengikuti ekstrakurikuler sebesar 63,8679 dan standar deviasi sebesar 5,18537 dengan total subjek 29 siswa. Sedangkan pada siswa yang tidak mengikuti ekstrakurikuler yang terdapat nilai mean sebesar 61,5338 dan standar deviasi sebesar 3,97923 dengan total subjek 34 siswa. 
Tabel 2. Kategoriasi prokrastinasi akademik siswa yang mengikuti ekstrakurikuler

\begin{tabular}{|c|c|c|c|}
\hline $\begin{array}{c}\text { Rumus } \\
\text { Interval }\end{array}$ & Kategori & Jumlah & $\begin{array}{c}\text { Persentase } \\
\%\end{array}$ \\
\hline $\begin{array}{c}56,09< \\
X \leq 61,27\end{array}$ & Rendah & 7 & $24,14 \%$ \\
\hline $\begin{array}{c}61,27< \\
\underline{X}<66,46 \\
\end{array}$ & Sedang & 15 & $51,72 \%$ \\
\hline $\begin{array}{c}66,46< \\
X \leq 71,65 \\
\end{array}$ & Tinggi & 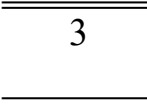 & $10,34 \%$ \\
\hline $\begin{array}{c}71,65< \\
X \\
\end{array}$ & $\begin{array}{l}\text { Sangat } \\
\text { Tinggi }\end{array}$ & 4 & $13,79 \%$ \\
\hline Total & & 29 & $100 \%$ \\
\hline
\end{tabular}

Tabel 3. Kategoriasi prokrastinasi akademik siswa yang tidak mengikuti ekstrakurikuler

\begin{tabular}{|c|c|c|c|}
\hline $\begin{array}{l}\text { Rumus } \\
\text { interval }\end{array}$ & Kategori & Jumlah & $\begin{array}{c}\text { Presentase } \\
(\%)\end{array}$ \\
\hline $\begin{array}{l}55,56<X \\
\leq 59,54\end{array}$ & Rendah & 10 & $29,41 \%$ \\
\hline $\begin{array}{l}59,54<X \\
\leq 63,52\end{array}$ & Sedang & 13 & $38,24 \%$ \\
\hline $\begin{array}{l}63,52<X \\
\leq 67,50\end{array}$ & Tinggi & 8 & $23,53 \%$ \\
\hline $6750<x$ & $\begin{array}{l}\text { Sangat } \\
\text { Tinggi }\end{array}$ & 3 & $8,82 \%$ \\
\hline Total & & 34 & $00 \%$ \\
\hline
\end{tabular}

\section{Analisis Deskriptif}

a) Uji Normalitas

Tabel 4. Hasil uji normalitas

\begin{tabular}{lll}
\hline \multicolumn{1}{c}{ Variabel } & $\begin{array}{c}\text { Kolmogorov- } \\
\text { Smirnov }\end{array}$ & Sig. \\
\hline Ekstrakurikuler & 1,032 & 0,237 \\
\hline $\begin{array}{l}\text { Non- } \\
\text { Ekstrakurikuler }\end{array}$ & 0,650 & 0,793 \\
\hline
\end{tabular}

Nilai signifikan pada siswa yang mengikuti ekstrakurikuler sebesar 0,237 dan pada siswa yang tidak mengikuti ekstrakurikuler menunjukkan nilai signifikan sebesar 0,793. Nilai ini lebih besar dari 0,05, ini menunjukkan bahwa data variabel prokrastinasi akademik terdistribusi secara normal. b) Uji Homogenitas

Tabel 5. Hasil uji homogenitas

\begin{tabular}{c}
$\frac{\text { Prokrastinasi akademik }}{\text { Levene Statistic }}$ \\
\hline 1,668 \\
\hline
\end{tabular}

Nilai signifikan statistik uji Levene adalah 0,212. Nilai signifikan ini lebih besar dari taraf signifikan 0,05 . Sehingga dapat disimpulkan bahwa data kedua kelompok yaitu siswa yang mengikuti ekstrakurikuler dan siswa yang tidak mengikuti ekstrakurikuler memiliki varians yang sama (homogen).

c) Uji Hipotesis

Tabel 6. Hasil uji hipotesis

Independent Samples Test

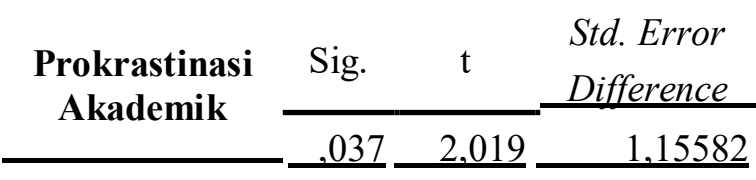

Rata-rata skor prokrastinasi akademik yang diperoleh siswa yang mengikuti ekstrakurikuler yaitu 63,87 lebih tinggi dibandingkan dari siswa tidak yang mengikuti ekstrakurikuler yaitu 61,53. Selisi rata-rata skor prokrastinasi akademik antara siswa yang mengikuti ekstrakurikuler dengan yang tidak mengikuti ekstrakurikuler sebesar 2,34 hal ini menunjukan bahwa keduanya memiliki kecenderungan prokrastinasi akademik walaupun tidak terpaut jauh nilai skor rataratanya.

Hasil data menunjukkan nilai signifikan 0,037. Nilai ini lebih kecil dari 0,05 , sehingga dapat disimpulkan bahwa siswa yang mengikuti ekstrakurikuler memiliki prokrastinasi akademik yang tinggi dibandingkan dengan siswa yang tidak mengikuti ekstrakurikuler di 
SMA Negeri 1 Kendari tahun pelajaran 2019/2020.

\section{A. Pembahasan}

Berdasarkan uji hipotesis yang telah dilakukan, peneliti melihat beberapa faktor yang dapat mempengaruhi timbulnya prokrastinasi akademik pada siswa yang mengikuti ekstrakurikuler dengan siswa yang tidak mengikuti ekstrakurikuler, berdasarkan penelitian yang dilakukan oleh Jannah \& Muis (2014) mengungkapkan bahwa tidak semua siswa memiliki kemampuan untuk mengatur waktu dengan baik, terutama ini biasanya terjadi pada siswa yang mengikuti kegiatan ekstrakurikuler atau organisasi di sekolah, sering kali siswa malas menghadapi tugas-tugas sekolah dan siswa cenderung melakukan penundaan tugas akan cenderung mengerjakannya terburuburu. Hal ini menyiratkan ketidakpastian prioritas, tujuan dan objektivitas pelaku, keikutsertaan siswa dalam kegiatan ekstrakurikuler maupun organisasi menjadikan siswa harus mengatur waktunya antara kegiatan akademik dan non-akademik sehingga fokus siswa yang aktif dalam organisasi menjadi terbagi antara aktivitas pembelajaran dan aktivitas organisasi.

Hal ini diperkuat oleh penelitian Yaningsih \& Fachrurrozie (2018) bahwa keaktifan siswa dalam ekstrakurikuler(33,7\%) berpengaruh positif terhadap prokrastinasi akademik, dan siswa disarankan untuk mengurangi kebiasaan menunda baik kegiatan akademik maupun diluar akademik. Penelitian mengenai prokrastinasi akademik pada siswa SMA Negeri 1 Kendari dengan jumlah subjek 63 siswa diantaranya siswa yang mengikuti ekstrakurikuler sebanyak 29 siswa dan siswa yang tidak mengikuti ekstrakurikuler sebanyak 34 siswa. Diperoleh hasil berdasarkan siswa yang mengikuti ekstrakurikuler diperoleh 7
$(24,14 \%) \quad$ siswa mengalami prokrastinasi akademik berada pada kategori rendah, sebanyak $15(51,72 \%)$ siswa mengalami prokrastinasi sedang, ada $3(10,34 \%)$ siswa mengalami prokrastinasi tinggi, dan hanya 4 $(13,79 \%)$ siswa mengalami prokrastinasi sangat tinggi. Sedangkan pada kategorisasi siswa yang tidak mengikuti ekstrakurikuler diperoleh 10 $(29,41 \%)$ siswa mengalami prokrastinasi akademik pada kategori rendah, sebanyak $13(38,24 \%)$ siswa mengalami prokrastinasi sedang, ada 8 $(23,53 \%)$ siswa mengalami prokrastinasi tinggi, dan hanya 3 $(8,82 \%)$ siswa mengalami prokrastinasi sangat tinggi. Berdasarkan kategori tersebut diperoleh hasil bahwa siswa yang mengikuti ekstrakurikuler maupun tidak mengikuti ekstrakurikuler memiliki prokrastinasi akademik pada kategori sedang yakni jumlah persentase lebih tinggi dibanding kategori rendah, tinggi dan sangat tinggi. Berdasarkan hasil penelitian diperoleh adanya perbedaan rata-rata skor prokrastinasi akademik yang dilakukan oleh siswa yang mengikuti ekstrakurikuler dengan yang tidak mengikuti ekstrakurikuler di SMA Negeri 1 Kendari.

Rata-rata skor prokrastinasi akademik yang diperoleh siswa yang mengikuti ekstrakurikuler yaitu 63,87 lebih tinggi dibandingkan dari siswa tidak yang mengikuti ekstrakurikuler yaitu 61,53. Selisi rata-rata skor prokrastinasi akademik antara siswa yang mengikuti ekstrakurikuler dengan yang tidak mengikuti ekstrakurikuler sebesar 2,34 hal ini menunjukan bahwa keduanya memiliki kecenderungan prokrastinasi akademik walaupun tidak terpaut jauh nilai skor rata-ratanya.

Penelitian ini telah diusahakan dan dilaksanakan sesuai dengan prosedur ilmiah, namun masih memiliki keterbatasan, yaitu kurangnya waktu yang diberikan oleh pihak sekolah 
membuat proses pengisian skala oleh responden menjadi terburu-buru sehingga dapat menyebabkan jawaban yang diberikan oleh responden tidak menunjukkan keadaan yang sesungguhnya.

\section{Kesimpulan dan Saran \\ Kesimpulan}

1. Berdasarkan norma kategorisasi prokrastinasi akademik siswa yang mengikuti ekstrakurikuler diperoleh 7 siswa mengalami prokrastinasi akademik berada pada kategori rendah, sebanyak 15 siswa mengalami prokrastinasi sedang, ada 3 siswa mengalami prokrastinasi tinggi, dan hanya 4 siswa mengalami prokrastinasi sangat tinggi. Rata-rata skor prokrastinasi akademik yang diperoleh siswa yang mengikuti ekstrakurikuler yaitu 63,87

2. Norma kategorisasi prokrastinasi akademik siswa yang tidak mengikuti ekstrakurikuler diperoleh 10 siswa mengalami prokrastinasi akademik pada kategori rendah, sebanyak 13 siswa mengalami prokrastinasi sedang, ada 8 siswa mengalami prokrastinasi tinggi, dan hanya 3 siswa mengalami prokrastinasi sangat tinggi. Rata-rata skor prokrastinasi akademik yang diperoleh siswa yang tidak mengikuti ekstrakurikuler yaitu 61,53

3. Terdapat perbandingan antara siswa yang mengikuti ekstrakurikuler dengan yang tidak mengikuti ekstrakurikuler. Selisi rata-rata skor prokrastinasi akademik antara sebesar 2,34.

\section{Saran}

\section{Bagi Siswa}

Sebagai informasi agar siswa lebih memperhatikan dan mengatur jadwal belajar dengan membuat schedule agar dapat mengurangi prokrastinasi akademik yang terjadi.

\section{Bagi Guru}

Sebagai informasi bagi guru untuk membuat metode pembelajaran yang menarik seperti metode debat atau role playing agar siswa mempunyai semangat untuk mengerjakan pekerjaan rumah (PR) tanpa rasa ragu.

3. Bagi Peneliti Selanjutnya

Agar meneliti tentang variabel lain seperti time disorganisation, keadaan fisik individu, karakteristik tugas, sikap dan keyakinan, kondisi psikologis individu, anxiety, dukungan sosial, gaya pengasuhan orang tua, hostility with other, dan kondisi lingkungan yang mungkin dapat menyebabkan terjadinya prokrastınasi akademık yang lebın berpengaruh pada siswa dan tidak hanya melakukan penyebaran angket namun juga memberikan perlakuan atau memberi solusi agar tingkat prokrastinasi akademik dapat berkurang.

\section{Daftar Pustaka}

Emzir. (2014). Metodologi penelitian pendidikan kuantitatif dan kuliatatif. Jakarta: Rajawali Pers.

Jannah, M., \& Muis, T. (2014). Prokrastinasi akademik (perilaku penundaan akademik) mahasiswa fakultas ilmu pendidikan universitas negeri surabaya. Jurnal BK UNESA, (Online), Vol. 04, No.03: 2.

Kemdikbud. (2017). Tiga kegiatan dalam sekolah lima hari intrakurikuler korikuler dan ekstrakurikuler. Diunduh dari: https://www.kemdikbud.go.id/ 
Marliani, N. (2015). Peningkatan kemampuan berpikir kreatif matematis siswa melalui model pembelajaran missiori matematis siswa project (MMP). Jurnal formatif, Vol $5(1)$.

Rakhmanti, M. N. (2014). Pengaruh keaktifan siswa dalam kegiatan ekstrakurikuler dan kebiasan belajar siswa terhadap prestasi belajar siswa program keahlian teknik bangunan SMK Negeri 2 Pengasih. (Skripsi). Yogyakarta: UNY.

Ristekdikti. (2016). Undang-undang republik indonesia nomor 20 tahun 2003. Diunduh dari: https://kelembagaan.ristekdikt i.go.id/.

Tuckman, B. W. (1990). Measuring procrastination attitudinally and behaviorally. Journal of American Educational Research Association, Vol. 51, No.4, 1-12.

Yaningsih, S., \& Fachrurrozie. (2018). Self-regulated learning memoderasi pengaruh media sosial, ekstrakurikuler, dan teman sebaya terhadap prokrastinasi akademik. Journal Economic Education Analysis. ISSN 2252-6544. 